\title{
Application of Wine Pomace seeds as finning agent during production of red wines and its effects over colour parameters
}

\author{
Hatice Kalkan Yıldırım¹ ${ }^{1}$ Burçak İşçi ${ }^{2}$, and Ahmet Altındişli ${ }^{2}$ \\ ${ }^{1}$ Department of Food Engineering, Ege University, 35100 Bornova, Izmir, Turkey \\ ${ }^{2}$ Department of Horticulture, Agriculture Faculty, Ege University, 35100 Bornova, Izmir, Turkey
}

\begin{abstract}
During production of wines are used different fining agents with animal origin for preventing later presipitation and reducing harshenss of wines. Even these positive properties they may cause some allergic reactions in consumers with allergic predispositons. Due to health concern wine pomace seeds could be a new alternative as fining agent with plant origin. In this study were evaluated preliminary effects of seeds over wine qulity expecially wine colour. As the next stage will be considered thier health effects.

Grapes of Vitis vinifera L. cvs. "Cabernet Sauvignon" were manually harvested at optimum maturity $\left(25^{\circ}\right.$ Brix $)$ and transported to the Experimental Winery at the Department of Food Engineering, Ege University, Izmir, Turkey. Wine production were done according to the accepted wine production procedures with exeption of $\mathrm{SO}_{2}$ (it was not added). Obtained grape seeds flour (drying and milling) were used as fining agent with different values $(2 / 4 / 6 / 8 / 10$ gram $/ 100 \mathrm{ml})$. In all wines basic wine chemical parameters and some spesific colour parameters were determined \%D280, \%D420, \%D520, \%D620, CD: Colour density, CI: Colour intensity, T: Tint value, dA \%: Proportion of red colour produced by flavylium cations , \% Y: Proportion of yellow colour, \% R: Proportion of red colour and \% B: Proportion of blue colour.

The results demonstrated the possibility of using wine pomace grape seeds as fining agent. Concidering colour parametrs of obtianed wines the best results were deterrmined with $8 \mathrm{~g} / 100 \mathrm{ml}$ application. Futher studies are needed in order to evaluate other wine parameters.
\end{abstract}

\section{Introduction}

An important step in winemaking is the addition of fining agents to adsorb undesirable products of fermentation such as odour and to aid wine stability. Polymerized tannins and heat-unstable proteins are removed by fining agents. Common fining agents include bentonite, egg white, gelatin, carbon and polyvinylpolypyrrolidone (PVPP).

Bentonite is a negatively charged clay with complex hydrated aluminium silicate components. It adsorbs positively charged molecules, such as protein and anthocyanins, and aided by gravity, particles sink to the bottom of the container. Bentonite is not reactive towards small phenolic compounds but binds large phenolic compounds such as anthocyanins and may also bind phenolic compound complexes with protein.

Egg white is an example of a fining agent with a positive surface charge that removes excess negatively charged tannins. The albumen of egg white is composed of peptide linkages that form hydrogen bonds with the hydroxy groups of tannins. Upon neutralization, the particles agglomerate and settle to the bottom due to increased mass.

Gelatins are also positively charged and are used for the removal of excess tannins from wine. They bind with larger molecules with more phenolic groups that allow more hydrogen bonding sites. Subsequent counter fining with a silica solution such as Kieselsol is recommended to prevent haze formation.

Kieselsol also forms a network of fibres that aid in the removal of tannins and negatively charged particles.
This interaction depends on particle size, particle shape, surface characteristics and particle size distribution within the suspension.

PVPP is a synthetic polymer that complexes with phenolic and polyphenolic wine components by hydrogen bond formation. It has an affinity for low molecular weight phenols due to the rigidity of the crosslinked PVPP structure.

Isinglass is a positively charged fining agent derived from the air bladder of the sturgeon. It is available as a liquid, sheet or flocculated isinglass [1].

The aim of this study was to find an new more economical and healthy finning agent.

\section{Materials and methods}

\subsection{Winemaking}

Grapes of Vitis vinifera L. cvs. "Cabernet Sauvignon" were manually harvested at optimum maturity $\left(25^{\circ}\right.$ Brix $)$ and transported to the Experimental Winery at the Department of Food Engineering, Ege University, Izmir, Turkey. Wine production were done according to the accepted wine production procedures.

After alcohol fermentation (sugar content below $1.5 \mathrm{~g} / \mathrm{L}$ ), the wines were racked and prepared for fining. Grape seeds flour (drying and milling) were used as fining agent with different values (2/4/6/8/10 gram/100 ml).

After filtration (filter plate: Seitz, D.6800 - Manheim) and bottling, wines were stored at $5^{\circ} \mathrm{C}$. 
Table 1. Application.

\begin{tabular}{|l|l|c|}
\hline \multirow{4}{*}{ Control } & nm value & Absorbance value \\
\hline & $420 \mathrm{~nm}$ & 0,439 \\
\cline { 2 - 3 } & $520 \mathrm{~nm}$ & 0,496 \\
\cline { 2 - 3 } $2 \mathrm{~g}$ & $620 \mathrm{~nm}$ & 0,256 \\
\hline \multirow{4}{*}{$4 \mathrm{~g}$} & $420 \mathrm{~nm}$ & 0.430 \\
\cline { 2 - 3 } & $520 \mathrm{~nm}$ & 0.486 \\
\cline { 2 - 3 } & $620 \mathrm{~nm}$ & 0.239 \\
\hline \multirow{3}{*}{$6 \mathrm{~g}$} & $420 \mathrm{~nm}$ & 0.434 \\
\cline { 2 - 3 } & $520 \mathrm{~nm}$ & 0.486 \\
\cline { 2 - 3 } & $620 \mathrm{~nm}$ & 0.236 \\
\hline \multirow{3}{*}{$8 \mathrm{~g}$} & $420 \mathrm{~nm}$ & 0.431 \\
\cline { 2 - 3 } & $520 \mathrm{~nm}$ & 0.480 \\
\cline { 2 - 3 } & $620 \mathrm{~nm}$ & 0.235 \\
\hline \multirow{3}{*}{$10 \mathrm{~g}$} & $420 \mathrm{~nm}$ & 0.440 \\
\cline { 2 - 3 } & $520 \mathrm{~nm}$ & 0.479 \\
\cline { 2 - 3 } & $620 \mathrm{~nm}$ & 0.243 \\
\cline { 2 - 3 } & $420 \mathrm{~nm}$ & 0.472 \\
\cline { 2 - 3 } & $520 \mathrm{~nm}$ & 0.507 \\
\hline
\end{tabular}

Table 2. Colour analysis.

\begin{tabular}{|c|c|c|c|c|c|c|c|c|c|c|c|c|c|c|c|c|c|c|}
\hline & \multicolumn{3}{|c|}{ Control } & \multicolumn{3}{|c|}{$2 g$} & \multicolumn{3}{|c|}{$4 g$} & \multicolumn{3}{|c|}{$6 g$} & \multicolumn{3}{|c|}{$8 g$} & \multicolumn{3}{|c|}{$10 \mathrm{~g}$} \\
\hline & $\mathrm{L}$ & $a^{*}$ & $b^{*}$ & $\mathrm{~L}$ & $\mathrm{a}^{*}$ & $\mathrm{~b}^{*}$ & $\mathrm{~L}$ & $a^{*}$ & $\mathrm{~b}^{*}$ & $\mathrm{~L}$ & $a^{*}$ & $b^{*}$ & $\mathrm{~L}$ & $a^{*}$ & $\mathrm{~b}^{*}$ & $\mathrm{~L}$ & $\mathrm{a}^{*}$ & $\mathrm{~b}^{*}$ \\
\hline Avg & 0.30 & 0.42 & 0.29 & 0.16 & 0.33 & 0.11 & 0.75 & 0.63 & 0.25 & 0.19 & 0.55 & 0.16 & 0.30 & 0.68 & 0.21 & 0.50 & 1.24 & $\overline{0.45}$ \\
\hline Std & 05 & 10 & 0.1 & .01 & 0. & 0.02 & 0.06 & 0.33 & 0.34 & 0.02 & 0.10 & 0.05 & 0.05 & 13 & 0.09 & 0.03 & 0.20 & 0.15 \\
\hline P-P & 11 & 0.23 & 0.26 & .02 & 0.20 & 0.05 & 0.14 & 0.72 & 0.73 & 0.05 & 0.23 & 0.11 & 0.13 & 0.26 & 0.18 & 0.08 & 0.43 & 0.31 \\
\hline $4 / 4$ & 30 & 0.47 & 0.21 & 0.15 & 0.39 & 0.09 & 0.77 & 0.74 & 0.51 & 0.17 & 0.44 & 0.13 & 0.28 & 0.58 & 0.27 & 0.53 & 1.36 & 0.53 \\
\hline $3 / 4$ & 0.26 & \begin{tabular}{|l|}
0.54 \\
\end{tabular} & 0.20 & 0.16 & 0.21 & 0.08 & 0.67 & 0.75 & 0.23 & 0.19 & 0.59 & 0.16 & 0.31 & 0.56 & 0.27 & 0.50 & 1.27 & 0.2 \\
\hline $2 / 4$ & 0.37 & \begin{tabular}{|l|}
0.36 \\
\end{tabular} & 0.46 & 0.16 & 0.31 & 0.12 & 0.81 & 0.14 & 0.48 & 0.17 & 0.49 & 0.12 & 0.37 & 0.82 & 0.23 & 0.51 & 1.38 & 0.5 \\
\hline $1 / 4$ & 0.29 & \begin{tabular}{|l|}
0.32 \\
\end{tabular} & 0.28 & 0.17 & 0.40 & 0.13 & 0.76 & 0.87 & -0.22 & 0.22 & 0.67 & 0.22 & 0.24 & 0.75 & 0.09 & 0.45 & 0.95 & 0.5 \\
\hline
\end{tabular}

\subsection{Standard chemical analysis}

Titratable acidity, $\mathrm{pH}$ and density values were determined in must [2] Additionally, the density, ethanol content, $\mathrm{pH}$, total acidity, volatile acidity, dry matter, ash, reducing sugar and protein content were determined in wines [3].

\subsection{Spectrophotometric colour analysis}

Absorbance measurements were done on a spectrophotometer (Pharmacia LKB, Novaspec ${ }^{\circledR}$ II, Uppsala, Sweden) with a $1.0 \mathrm{~mm}$ path lenght glass cells. The samples were clean and contained no $\mathrm{CO}_{2}$. Absorbance (A) values at 420, 520 and $620 \mathrm{~nm}$ were measured and Glories parameters were determined from these absorbance values:

$(\mathrm{CD})$ Colour Density $=(A 420+A 520)$

(CI) Colour Intensity $=(A 420+A 520+A 620)$

(T) Tint value $=(A 420 / A 520)$

(dA \%) Proportion of red colour produced by flavylium cations $=\left(\frac{A 520-\frac{A 420-A 620}{2}}{A 520} \times 100\right)$

$(\mathrm{Y} \%)$ Proportion of yellow colour $=\left(\frac{A 420}{C I} \times 100\right)$

$(\mathrm{R} \%)$ Proportion of red colour $=\left(\frac{A 520}{C I} \times 100\right)$

$(\mathrm{B} \%)$ Proportion of blue colour $=\left(\frac{A 620}{C I} \times 100\right)$

\subsection{Statistical evaluation}

The data were evaluated by two-way analysis of variance (ANOVA) to test the influence of the main factors (fermentation time and temperature) and interaction of them. Significant differences between averages were obtained at the $95 \%$ significance level. By using a PostHoc test, the least significant differences (LSD) test was performed.

\subsection{Results and discussion}

Colour is a perceptual phenomen that depends on the observer and the conditions in which the colour is observed. It is a characteristic of light, which is measurable in therms of intensity and wavelength. The selective adsorption of different amounts of the wavelengths within the visible region determines the colour of the object.

Hue is a quality by which one colour is distinguished from other another. It is a attribute corresponding to whether the object is red, orange, yellow, blue or violet. This perception of colour results from differences in absorption of radiant energy at various wavelenghts. If the shorter wavelennghts of $425 \mathrm{~nm}$ to $490 \mathrm{~nm}$ are reflected to a greater extend than the other wavelengths, the color is described as blue. Maximum reflection in the medium wavelength range results in green or yellow colour. Maximum reflectance at the longer wavelengths of $640-740 \mathrm{~nm}$ indicates red objects. Hue is defined on the Munsell colour tree in the circumferential direction by five 
principal (R: red, Y: yellow, G: green, B:blue, P:purple) and five intermediates $[4,5]$.

Chroma is the quality that distinguishes a pure hue from a gray shade. The chroma (saturation or purity) axis extendeds from the value (lightness) axis towards the pure hue. A pastel tint has low saturation while pure color is said to have high saturation [4].

Concidering colour parametrs of obtained wines the best results were determined with $8 \mathrm{~g} / 100 \mathrm{ml}$ application (Tables 1, 2).

\section{Conclusions}

The results demonstrated the possibility of using wine pomace grape seeds as fining agent. Futher studies are needed in order to evaluate other wine parameters.

\section{References}

[1] Threlfall, R. T., Morris, J. R. and Mauromoustakos, A., Effects of fining agents on trans-resveratrol concentration in wine. Aust. Journal of Grape and Wine Research (1999)

[2] OIV, Compendium of International Methods of Wine and Must Analysis, Paris: International Organization of Vine and Wine (1990)

[3] OIV, Compendium of International Methods of Wine and Must Analysis, Paris: International Organization of Vine and Wine (2005)

[4] Sahin, S. \& Sumnu, S.G., Physical Properties of Foods, Springer, 257. pp. (2006)

[5] Hatice K. Yildırım, Effects of Fining Agents on Antioxidant Capacity of Red Wines. Journal of The Institute of Brewing, 117: 55-60 (2011) 